\title{
On the role of market insurance in a dynamic model
}

\author{
Helge Braun · Winfried Koeniger
}

Published online: 21 June 2007

(C) The Geneva Association 2007

\begin{abstract}
Durables like cars or houses are a substantial component in the balance sheets of households. These durables are exposed to risk and can be insured in the market. We build a dynamic model in which agents have three possibilities to cope with the risk exposure of the durable stock: (i) purchase of market insurance, (ii) buffer-stock saving of the riskless asset or (iii) adjustment of the durable stock. We calibrate our model to the US economy and find a small role for market insurance.
\end{abstract}

Keywords Consumption · Durables · Uncertainty · Insurance ·

Buffer-stock wealth

JEL Classification $\quad \mathrm{D} 81 \cdot \mathrm{E} 21 \cdot \mathrm{G} 22$

\section{Introduction}

Durables are very important in the balance sheets of households. In terms of flows, durable consumption accounts for $12-28 \%$ of total consumption in the US in the period 1990-2002 (depending on whether durable consumption includes housing services; see also Attanasio [1999]). In terms of stocks, the current-cost net stock of

\footnotetext{
H. Braun · W. Koeniger $(\bowtie)$

IZA, P.O. Box 7240, 53072 Bonn, Germany

e-mail: koeniger@iza.org

H. Braun

University of British Columbia, \#997-1873 East Mall,

Vancouver, BC, Canada V6T 1Z1

e-mail: hbraun@interchange.ubc.ca
} 
private fixed assets amounts to $130 \%$ of disposable income where alone the stock of consumer durables accounts for $40 \%$ of this income. ${ }^{1}$

The stock of durables is exposed to risk: houses can be broken into or destroyed by natural catastrophes and cars can be stolen. We propose a dynamic model that allows the agent to manage this risk in three different ways through (i) purchase of market insurance, (ii) buffer-stock saving of a riskless asset or (iii) adjustment of the durable stock. The goal of this paper is to analyze the qualitative interplay and quantitative importance of these three ways in which the consumer can manage his risk.

Compared with previous research that did not allow for endogenous adjustment of the durable stock and thus an endogenous size of the loss [Gollier, 2003], we find that the policy function for market insurance can be interestingly non-monotonic in the agent's resources. The reason is that two opposite forces are at work which are endogenous in our model: the size of the loss and self-insurance through bufferstock saving. An intuitive explanation for the non-monotonicity is that the covariance between the marginal utility of non-durable consumption and the loss is small for a small durable stock (and thus a negligible loss) as well as for a large durable stock if the agent holds enough risk-free assets to self-insure. It is in the intermediate range that market insurance plays a role.

Another contribution of this paper is that we check whether endogenous interest rates in a closed economy alter the results on the role of market insurance. This is important quantitatively because buffer-stock saving becomes more relevant compared with market insurance if the difference between the discount and interest rate is small. This difference measures the cost of saving for the impatient agent.

We calibrate our model to the US economy and find that market insurance only plays a small role for consumer welfare unless insurance is important in permitting the use of durables as collateral. Even in this case, however, the deductible or retention ratio is an order of magnitude higher than observed in reality.

Our paper builds on the literature that has explored market insurance mostly in a static framework. For example, Ehrlich and Becker [1972] show that market insurance and actions of agents that decrease the size of the loss are substitutes. Instead, Eeckhoudt et al. [1997] show that market insurance is more desirable if the share of a risky asset in the portfolio increases (if the utility function has the property of decreasing absolute risk aversion). Moreover, Eeckhoudt et al. [1991], Proposition 2, find that market insurance and precautionary savings are substitutes for a particular increase in risk.

Although these static results have been very helpful to understand particular interactions between market insurance and other policies, they cannot be used to address the question whether there is a role for market insurance in the first place within a simple dynamic neoclassical framework. The most important contributions in the literature in this respect are by Gollier [1994, 2003] who investigates dynamic interactions between market insurance and the accumulation of risk-free assets as buffer stock. Whereas Gollier [1994] derives a closed form solution for CRRA utility and no liquidity constraints in a continuous-time model, Gollier [2003]

\footnotetext{
1 The figures are obtained from the national income and product accounts of the Bureau of Economic Analysis, U.S. Department of Commerce.
} 
provides a numerical solution to the more general problem. He finds that time diversification through buffer-stock saving reduces the scope for market insurance substantially. As mentioned above, we show in this paper that his assumptions of an exogenous insurable risk and an exogenous interest rate are important and matter for some of the qualitative as well as quantitative results.

The rest of the paper is structured as follows. In Section 2, we present and discuss the model and its optimality conditions. In Section 3, we present the numerical solution for the small-open economy with an exogenous interest rate. We calibrate our model to match some target statistics in the US and show how the equilibrium changes if we vary important model parameters. In particular, we show how the use of secured durables as collateral or stochastic permanent labor income affect the equilibrium. Finally, we mention that market insurance is even less important if we allow for an endogenous interest rate in a closed-economy. In Appendix A we provide an analytic approximation of the policy functions for the special case of abundant financial wealth and in Appendix B we explain our numerical solution procedure which takes into account that wealth constraints may be binding.

\section{The model}

Agents are risk-averse and have an infinite horizon. They derive utility from a durable good $v$ and a non-durable good $c$. The instantaneous utility is given by $U(c, v)=u(c)+\phi w(v)$ where $u($.$) and w($.$) are both strictly concave, and \varphi$ is the weight assigned to utility derived from the durable. We assume that the marginal utility $w^{\prime}(v)$ is well defined at $v=0$ so that our model is able to generate agents with no durable stock in at least some states of the world, as is realistic. A possible functional form is $w(v)=(v+\underline{v})^{\tau}$, with $\tau \leq 1$ and $\underline{v} \geq 0$. The asymmetry in the utility function with respect to non-durable and durable consumption is justified in the sense that durables are less essential than non-durable consumption such as food.

In specifying utility as above, we have made a number of simplifying assumptions. We assume $v$ to be a homogenous, divisible good. Moreover, utility is separable over time and at each point in time it is separable between durables and non-durables. Both assumptions are made for tractability and clarity given that it is more realistic to assume that durables are a bundle of characteristics and that utility derived from durables depends on non-durable consumption in non-trivial ways. Instead, as in much of the literature, we assume that the service flow derived from durables is proportional to the stock where we have normalized the factor of proportionality to 1 (see Waldman [2003] for a critical review). We discuss these assumptions further in light of the results presented below.

We specify our model in discrete time. At the beginning of each period, financial wealth $a_{t}$, the durable stock $v_{t}$ and its insurance coverage denoted by $D_{t}$, the loss $l_{t}$ and labor income $y_{t}$ are predetermined. Given these state variables, the agent chooses non-durable consumption $c_{t}$, investment into the durable $d_{t}$, and insurance coverage for the next period $D_{t+1}$ subject to constraints which we mention below. Finally, the durable stock depreciates at rate $\delta$. This depreciation rate could be negative, in which case the value of the durable appreciates. Below, however, we 
focus on the case in which the durable depreciates as in most of the literature. As we will see, sensible changes in the depreciation rate are not important for the result that the role for market insurance in our model is small.

Since the durable stock $v_{t}$ is predetermined, utility is derived from the durable stock net of the loss. We implicitly assume that the insurance company does not replace the durable but reimburses the insured loss in cash which can then be transformed into durables only in the next period. In other words, we assume that the insurance company cannot adjust agents' durables more quickly than agents themselves. Thus, the consequences of one loss in terms of utility depend on the length of the period before durable adjustment may take place, which we calibrate as a quarter in our numerical solution. Although we think that this is a realistic assumption in terms of adjustment speed, below we mention the robustness of our results for a shorter period length of a month.

Before we lay out the dynamic program, let us characterize the insurance contract. A risk neutral insurer offers an actuarially unfair one-period insurance contract with a loading factor $\mu>1$. Such a contract is closest to the one-period saving technology and thus interesting to analyze in our framework. It is wellknown that in this case the optimal insurance contract has a deductible [Raviv, 1979]. Since we assume that the loss distribution has only two states (no loss or loss $l$ ), the choice of the deductible is equivalent to choosing the retention ratio $D$. This ratio is defined as the proportion of the loss $l$ which is not insured. Thus, should a loss occur, the agent receives the following payment from the insurance company

$$
\max (l-D l, 0)=l * \max (1-D, 0)=l *(1-D),
$$

where the last equality holds since $D \in[0,1]$. Defining $\mathbf{v}($.$) as the value function,$ the dynamic program is

$\mathbf{v}\left(a_{t}, v_{t}, D_{t} \mid l_{t}, y_{t}\right)=\max _{a_{t+1}, v_{t+1}, D_{t+1}}\left[u\left(c_{t}\right)+\phi w\left(v_{t}-l_{t}\right)+\beta E_{t} \mathbf{v}\left(a_{t+1}, v_{t+1}, D_{t+1} \mid l_{t+1}, y_{t+1}\right)\right]$

s.t.

$$
\begin{aligned}
& a_{t+1}=(1+r) a_{t}+y_{t}+\overbrace{\left(1-D_{t}\right) l_{t}}^{\text {insurance claim }}-c_{t}-d_{t}-\overbrace{\frac{\mu}{1+r}\left(1-D_{t+1}\right) E l_{t+1}}^{\text {insurance premium }} \\
& v_{t+1}=(1-\delta) v_{t}-l_{t}+d_{t} \\
& a_{s} \geq \underline{a}, s \geq t \\
& v_{s} \geq 0, s \geq t, \\
& D_{s} \in[0 ; 1], s \geq t,
\end{aligned}
$$

where $\beta$ is the discount factor, $r$ is the interest rate, and $\delta$ is the depreciation rate which we assume to be constant for simplicity. The expectation operator is $E$ where a subscript $t$ denotes that expectations are conditional on information available at time $t$. For the case of deterministic income $y_{t}=y$ where $y$ is non-random. We now discuss the constraints in some detail. 
The first constraint is the budget constraint. We implicitly assume that durables can be transformed into non-durable consumption with a linear technology so that the relative price is unity. The amount of assets tomorrow then depends on the amount of assets today plus the interest, the amount of durable and non-durable consumption, and labor income. Moreover, it depends on the amount of insurance demanded in period $t,(\mu /(1+r))\left(1-D_{t+1}\right) E l_{t+1}$, and the money received from the risk-neutral insurance company if damage occurred, $\left(1-D_{t}\right) l_{t}$. Note that insurance is actuarially unfair, $\mu>1$, so that risk-averse agents do not necessarily insure fully. Furthermore, premiums are discounted to the present since a premium payment today only provides coverage tomorrow. In the meanwhile the insurance company earns the market interest rate $r$ on the paid premium.

The second constraint is the law of motion of the durable stock. The size of the durable stock tomorrow depends on its size today net of depreciation minus the loss plus the investment today. In order to economize on notation in the equations, we assume that the loss is exogenous in this section. In the numerical part of the paper, the loss is endogenous, proportional to the size of the durable stock. Note also that we abstract from adjustment costs. What is important for our results is that there is no advantage in the adjustment of the durable if the agent purchases market insurance instead of self-insuring with financial assets. This would be the case, for example, if insurance companies directly reimbursed the agent in terms of durables. As we discussed above, we do not think that it is a plausible assumption that insurance companies can adjust durables faster than agents. In general, adjustment costs certainly would imply more realistic adjustment flows but have ambiguous predictions on the durable stock and hence on the risk which is borne by agents. For plausible parameters in dynamic models with durables like Luengo-Prado [2006], the effect of adjustment costs on the durable stock is quite small quantitatively so that we choose to abstract from adjustment costs as a starting point. For an analysis of durable investment under uncertainty with adjustment costs see also Bertola et al. [2005] or Lam [1991].

The third constraint is the solvency constraint. It implies that the agent cannot borrow more than $\underline{a}$ which guarantees repayment of the debt. Aiyagari [1994] derives in a model with non-durable consumption that $\underline{a}=-\frac{y_{l}}{r}$, where $y_{l}$ is the smallest $y$ attainable on the support of the distribution. For the numerical part of this paper we will assume $\underline{a}=0$, a tighter borrowing constraint unless $y_{l}=0$. Reducing $\underline{a}$ does not change our main numerical result since it only shifts financial assets down implying a wealth effect which is quantitatively small. Note further that the agent cannot use durables as collateral in this formulation. We relax this assumption in Section 3.1.2 where we allow agents to use their secured durable stock as collateral.

The fourth and fifth constraint imply that the agent cannot go short in the durable or sell insurance. Finally, for both state variables $a$ and $v$ a transversality condition has to be satisfied, respectively.

To gain intuition, let us ignore the constraints $a_{s} \geq \underline{a}, v_{s} \geq 0$ and $D_{s} \in[0 ; 1]$, in which case problem (1) yields the following Euler equations for the controls $c_{t}, d_{t}$ and $D_{t+1}$, respectively: 


$$
\begin{gathered}
u^{\prime}\left(c_{t}\right)=\beta(1+r) E_{t} u^{\prime}\left(c_{t+1}\right), \\
u^{\prime}\left(c_{t}\right)=\beta\left[(1-\delta) E_{t} u^{\prime}\left(c_{t+1}\right)+\phi E_{t} w^{\prime}\left(\widetilde{v}_{t+1}\right)\right]
\end{gathered}
$$

and

$$
u^{\prime}\left(c_{t}\right) \mu E l_{t+1}=\beta(1+r) E_{t}\left\{u^{\prime}\left(c_{t+1}\right) l_{t+1}\right\},
$$

where primes denote first-order derivatives of the functions with respect to the variables in brackets and $\widetilde{v}$ is the durable stock net of the loss. Equations (2) and (3) can be used to solve for the intertemporal behavior of $\widetilde{v}$ :

$$
E_{t} w^{\prime}\left(\widetilde{v}_{t+1}\right)=\beta(1+r) E_{t} w^{\prime}\left(\widetilde{v}_{t+2}\right) .
$$

We now provide some intuition for these intertemporal optimality conditions. Equation (2) is standard and relates non-durable consumption intertemporally. Equation (5) is the equivalent for the durable stock. More interestingly, on the left-hand side of equation (3) are the costs for one unit of durable investment $d$, in terms of utility derived from non-durable consumption. These have to equal the benefits on the right-hand side of equation (3). The benefits are the discounted expected utility afforded by the increase of the durable stock, $\phi E_{t} w^{\prime}\left(\widetilde{v}_{t+1}\right)$, plus the expected utility of non-durable consumption resulting from selling one unit of the durable stock after depreciation in the next period. ${ }^{2}$ Note that it is important that the agent derives utility from the durable in our model. Otherwise, the agent would not invest in the durable since it is risky and returndominated by the risk-free asset. $^{3}$

Equation (4) is the intertemporal optimality condition for insurance demand. Again, marginal costs on the left-hand side of the equation equal marginal benefits which are on the right-hand side. The marginal benefits are that the agent can consume more tomorrow in bad states of the world if he buys insurance today because in expectation more resources are available due to insurance payments. Since $E_{t}\left\{u^{\prime}\left(c_{t+1}\right) l_{t+1}\right\}=E_{t} u^{\prime}\left(c_{t+1}\right) E l_{t+1}+\operatorname{cov}\left(u^{\prime}\left(c_{t+1}\right), l_{t+1}\right)$, the agent wants to buy more insurance if large realizations of $l_{t+1}$ occur in states of the world in which the agent's non-durable consumption is already small. In terms of equation (4), a higher $\operatorname{cov}\left(u^{\prime}\left(c_{t+1}\right), l_{t+1}\right)$ implies a higher $u^{\prime}\left(c_{t}\right)$ : the marginal cost on the left-hand side is relatively higher because agents are willing to forego more non-durable consumption to buy more insurance. In order to understand the policy function for $D$ which we obtain in our numerical solutions, it is important to keep in mind that the attractiveness of insurance crucially depends on $\operatorname{cov}\left(u^{\prime}\left(c_{t+1}\right), l_{t+1}\right)$. As we will see below, the amount of risk-free assets $a$ and the size of the durable stock $v$ are both important for this covariance

\footnotetext{
${ }^{2}$ With an endogenous loss proportional to the durable stock, equation (3) is modified as follows: on the left-hand side of the equation an additional term captures the costs resulting from higher insurance payments because of a higher loss; on the right-hand side the expectation of the future durable stock takes into account that the size of the loss increases if the agent invests.

${ }^{3}$ Compared to standard portfolio-choice models, it is noteworthy that in our model utility functions with constant-relative-risk aversion do not imply that a constant share of wealth is invested in the risky asset.
} 
since they matter for the variability of $u^{\prime}\left(c_{t+1}\right)$ and the size of the loss $l_{t+1}$. In particular, we will assume that the size of the loss is proportional to the durable stock with proportionality factor $\eta$ so that

$$
l_{t+1}=\eta v_{t+1} .
$$

In this case, the amount of resources available to the household changes the size of the loss through the choice of the durable stock $v_{t+1}$.

Before we continue to solve the model numerically, let us mention that in our model precautionary motives arise even if the agent has abundant financial wealth. As mentioned above, this is because utility is derived from the durable stock net of the loss. Thus, the agent cannot smooth immediately the fluctuations in the durable stock. We show this explicitly in Appendix A where we provide an approximation of the model to gain intuition. The numerical solution does not rely on this approximation (see Appendix B).

\section{Numerical solution}

In this section we first solve the model numerically for the small-open economy in which the interest rate is exogenous and profits accrue to foreign insurers (the latter assumption is not important but simplifies the exposition). After we have shown how the solution of the model depends on the most important parameter values, we mention how our quantitative results change if we assume a closed economy so that the interest rate is endogenous and insurance profits are part of the domestic budget constraint.

\subsection{The small open economy}

Before we solve the model numerically we rewrite the maximization problem in terms of resources "cash-on-hand" $x_{t}$ which is commonly done in the literature to reduce the state-space. Cash-on-hand at the beginning of period $t$ is defined as

$$
x_{t} \equiv(1+r) a_{t}+y_{t}+\left(1-\delta-D_{t} \eta I_{t}\right) v_{t},
$$

the sum of risk-free assets and their returns, labor income, and the cash value of the durable asset after depreciation and net of the loss which remains after accounting for the retention rate $D_{t}$ and the insurance payments. Note that we assume that the loss $l_{t}=\eta I_{t} v_{t}$ depends on the durable stock $v_{t}$ with a proportionality factor $\eta$. Whether a loss occurs or not is summarized by the indicator variable $I_{t}$. This variable takes the value 1 if a loss of size $\eta v_{t}$ occurs which happens with probability $\lambda$, and the value 0 if no loss occurs. Recalling that $\widetilde{v}_{t}=\left(1-\eta I_{t}\right) v_{t}$ is the durable stock net of the loss, we can rewrite the value function as 


$$
\begin{aligned}
V^{+}\left(x_{t}, \widetilde{v}_{t}\right)= & \max _{a_{t+1}, v_{t+1}, D_{t+1}}\left[u(\underbrace{x_{t}-a_{t+1}-v_{t+1}-\frac{\mu}{1+r}\left(1-D_{t+1}\right) \eta \lambda v_{t+1}}_{c_{t}})\right. \\
& \left.+\phi w\left(\widetilde{v}_{t}\right)+\beta E_{t} V^{+}\left(x_{t+1}, \tilde{v}_{t+1}\right)\right] .
\end{aligned}
$$

We can further simplify the problem by noting that $\widetilde{v}_{t}$ is predetermined in period $t$ and that the additive separable term $\phi w\left(\widetilde{v}_{t}\right)$ does not affect the optimal choices of the consumer. Subtracting the additively separable term $\phi w\left(\widetilde{v}_{t}\right)$ from the value function $V^{+}\left(x_{t}, \widetilde{v}_{t}\right)$, we can define a transformed value function that does no longer depend on $\widetilde{v}_{t}$ :

$$
V\left(x_{t}\right) \equiv V^{+}\left(x_{t}, \widetilde{v}_{t}\right)-\phi w\left(\widetilde{v}_{t}\right)
$$

The transformed maximization problem is then

$$
\begin{aligned}
V\left(x_{t}\right)= & \max _{a_{t+1}, v_{t+1}, D_{t+1}}\left[u(\underbrace{x_{t}-a_{t+1}-v_{t+1}-\frac{\mu}{1+r}\left(1-D_{t+1}\right) \eta \lambda v_{t+1}}_{c_{t}})\right. \\
& \left.+\beta \phi E_{t} w\left(\widetilde{v}_{t+1}\right)+\beta E_{t} V\left(x_{t+1}\right)\right]
\end{aligned}
$$

s.t.

$$
\begin{aligned}
& a_{s} \geq \underline{a}, \quad v_{s} \geq 0, \quad D_{s} \in[0 ; 1], \quad x_{s}=(1+r) a_{s}+y_{s}+\left(1-\delta-D_{s} \eta I_{s}\right) v_{s} \\
& \text { with } s \geq t+1 .
\end{aligned}
$$

It is easy to verify that the problem (6) satisfies Blackwell's sufficient conditions for a contraction mapping. This allows us to solve numerically for the optimal value function $V$ and the corresponding policy functions using Chebychev polynomials to approximate the functions. In our algorithm we first search for an upper bound of cash-on-hand $\bar{x}$ at which the optimal policies $\left\{a_{t+1}, v_{t+1}, D_{t+1}\right\}$ imply that the maximal attainable cash-on-hand without a durable loss, $x_{t+1}^{\max }$, is smaller than this upper bound:

$$
x_{t+1}^{\max }=(1+r) a_{t+1}+y+(1-\delta) v_{t+1}<\bar{x} .
$$

Since we assume $\underline{a}=0$, the lower bound $\underline{x}=y$ gives us a compact state space. More details on the numerical solution of the problem are provided in Appendix B.

Table 1 displays the benchmark parameter values that we use to solve the model numerically. We calibrate one period as one quarter of a year so that the parameter values imply an annual risk-free interest rate of .01 [Mehra and Prescott, 1985] and a discount factor of .95 or a discount rate of .053 [Aiyagari, 1994]. Thus, agents are quite impatient in the benchmark of our computations for the small-open economy. 
Table 1 Benchmark parameters

\begin{tabular}{rrrr}
\hline$r=.0025$ & $\beta=.9873$ & $\delta=.0355$ & $\lambda=.0543$ \\
$\eta=.6$ & $\mu=1.3$ & $\phi=1.5$ & $\underline{v}=.1$ \\
$\sigma_{1}=2$ & $\sigma_{2}=2$ & $y=1$ & \\
\hline
\end{tabular}

It is well-known that $\beta<1 /(1+r)$ is necessary in models with incomplete markets for the stock of risk-free assets to be finite. Indeed, if marginal utility is convex, uninsured risk gives rise to a precautionary savings motive and the additional savings imply an interest rate below the discount rate in a closed production economy [Aiyagari, 1994]. Since holding the durable stock is costly, $\delta>0$, the results in Deaton and Laroque [1992] imply that cash-on-hand is finite in our model. Thus, in our computations for the small open economy, we choose values for the interest rate that are consistent with impatience and check in the next subsection which interest rates prevail in the closed economy.

Concerning the other parameter values, the annual depreciation rate implied by Table 1 is $15 \%$ which is consistent with micro evidence on cars provided by Alessie et al. [1997]. The probability of a loss per quarter, $\lambda=.05$, is an upper bound based on claim rates for property and casualty insurance in the US provided by the Insurance research council (http://www.ircweb.org). The loading factor (mark-up) for insurance is set to $\mu=1.3$, as in Gollier [2003], which is consistent with evidence on direct written premiums and claims for the US [Financial Services Fact Book, 2004].

We normalize labor income $y$ to 1 , and parametrize the utility functions

$$
u(c)=\frac{c^{1-\sigma_{1}}-1}{1-\sigma_{1}} \text { and } w(v)=\frac{(v+\underline{v})^{1-\sigma_{2}}-1}{1-\sigma_{2}},
$$

where as mentioned in the previous section, $\underline{v}>0$ allows the consumer to hold no durable stock. We set risk aversion for the non-durable and durable good $\sigma_{1}=\sigma_{2}=2$ which is well within the range of commonly used values, and assume $\underline{v}=.1$ which is rather small. Indeed, it turns out that this parameter is not important and can be set to negligibly small values without changing the quantitative results much. This is because the region of $v$ close to zero is not important in our simulations. Since we do not have any information on the remaining two parameters $\eta$ and $\varphi$, we set $\eta=.6$ and $\varphi=1.5$ so that we match three target statistics:

(i) a durable stock between $40 \%$ and $130 \%$ of disposable income, depending on whether we consider consumer durables or all private fixed assets (see the data of the Bureau of Economic Analysis mentioned in Section 1). In the calibration, we target the average of these values.

(ii) a flow of durable consumption between $12 \%$ and $28 \%$ of total consumption in the US in the period 1990-2002 (depending on whether durable consumption 


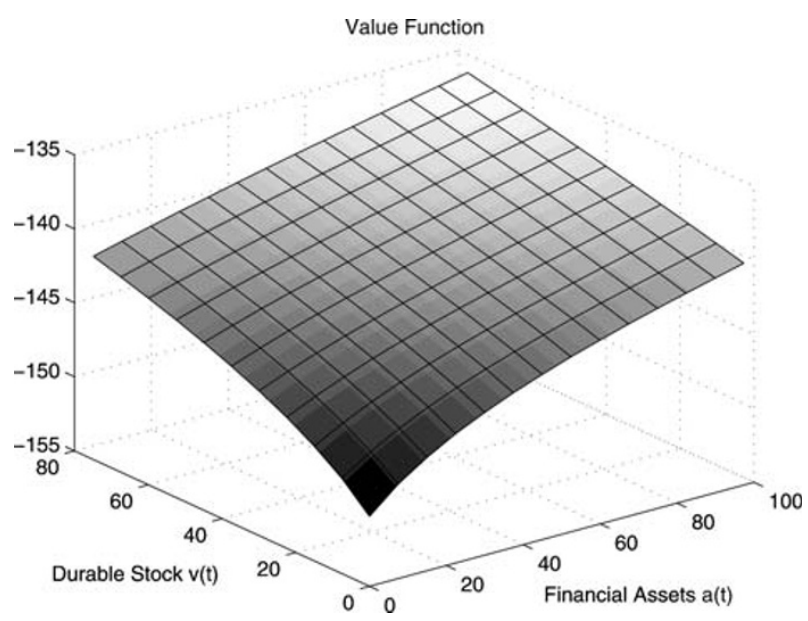

Fig. 1 Value function for the benchmark case. Note: the units of the durable stock and liquid assets are \% of disposable income

includes housing services; the source of the data is again the BEA). As above we target the average.

(iii) an expenditure on household property and casualty insurance including motor-vehicle insurance, of $2 \%$ of disposable income (see the Financial Service Fact Book, 2004).

Figure 1 displays the implied value function as a function of risk-free assets $a_{t}$ and the durable stock $v_{t}{ }^{4}$ Not surprisingly the value function is increasing and concave in both $a_{t}$ and $v_{t}$. More interestingly, Fig. 2 plots the policies as a function of cash-on-hand for our benchmark case. All variables but the retention ratio are expressed as percent of annual disposable income defined as the sum of quarterly interest and labor income $i \equiv r a+y$ multiplied by 4 .

Figure $2 \mathrm{~b}$ and $\mathrm{d}$ show that the planned durable stock and non-durable consumption are concave functions of cash-on-hand $x$. Both functions are quite steep as long as agents do not hold any risk-free assets and the marginal propensity to consume declines substantially as soon as agents hold a buffer stock of risk-free assets (see Fig. 2a). This shape of the consumption functions is similar as in the classic models of non-durable consumption with uninsured labor income risk and/or liquidity constraints [see Deaton, 1991; Carroll and Kimball, 1996, 2001]. Note that the agent only holds a positive amount of risk-free assets in our model because the durable stock is exposed to risk. If that were not the case, agents would consume all their resources and never hold a positive amount of risk-free assets since the rate of return on the risk-free asset is lower than the rate of time preference.

The main new result in our model is the policy function for the retention ratio $D$ that captures the importance of market insurance (see Fig. 2c). Whereas the expected deductible $\lambda \eta \nu D$ is increasing in cash-on-hand (see Fig. 2b), the retention

\footnotetext{
${ }^{4}$ Note that we iterate over $V\left(x_{t}\right)$ and then back out the implied value function over $a_{t}$ and $v_{t}$ after the algorithm has converged since this plot is slightly more informative.
} 

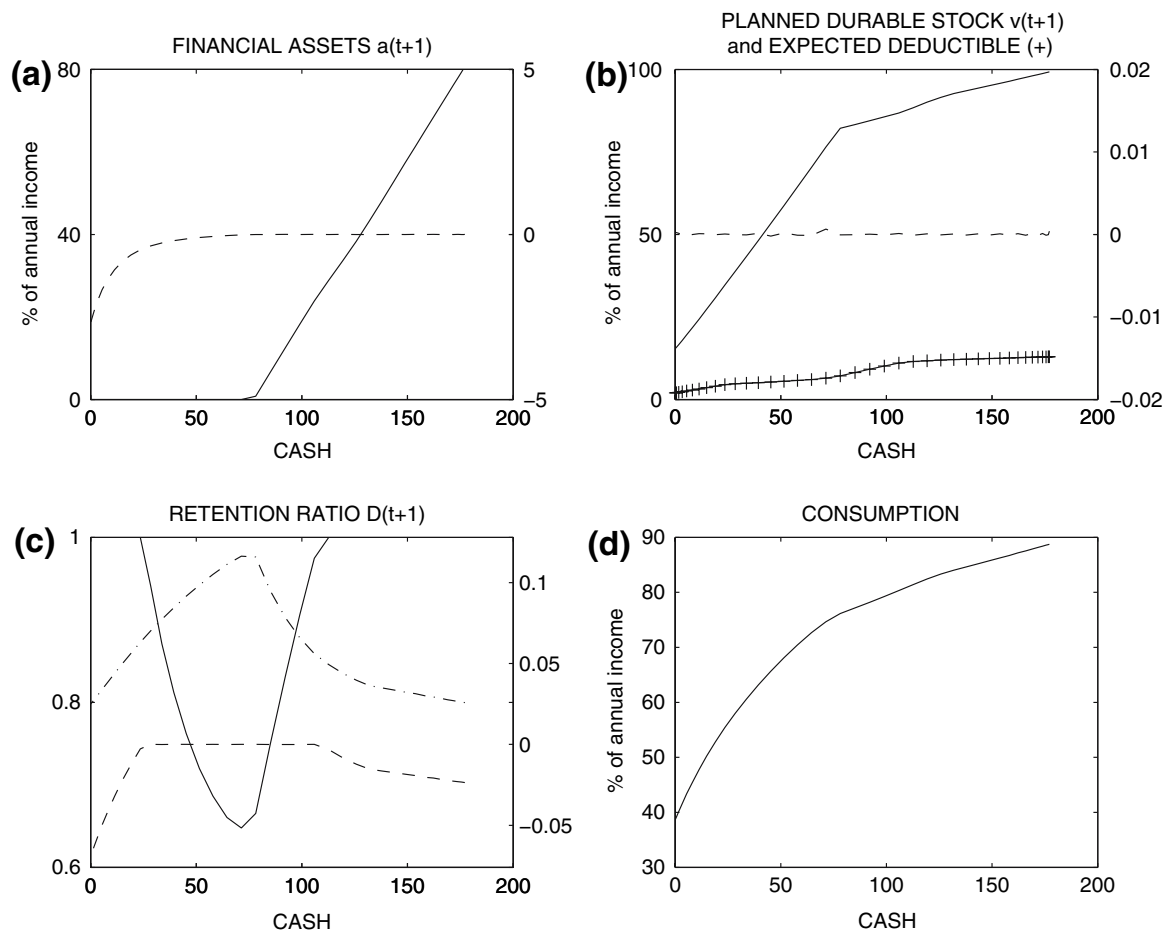

- policy --- foc (right scale) $\cdot-\cdot-\cdot \operatorname{cov}$ (right scale)

Fig. 2 Policies as a function of cash-on-hand $x_{t}$ for the benchmark parameters. Note: All variables but the retention ratio are in $\%$ of disposable income

ratio is interestingly non-monotonic as a function of cash-on-hand in our calibration. This is different to the results in Gollier [2003] where the retention ratio as well as the deductible monotonically increase as a function of cash-on-hand. The reason is that in our model the risk is endogenous and the durable stock is a part of total wealth $x$. The loss depends on the size of the durable and thus can be influenced by choices of the agent.

Notice first that market insurance is not desirable for high values of cash-on-hand if a sizeable amount of risk-free assets allows the agent to self-insure losses of the durable good. This mechanism implies that the retention ratio increases with cashon-hand as in Gollier [2003]. In our model, however, more cash-on-hand also implies a larger amount of the durable stock which increases the exposure but also makes any loss less important in terms of marginal utility. This effect reinforces that the retention ratio approaches 1 for large values of cash-on-hand. Low values of cash-on-hand instead imply a small amount of risk-free assets so that losses of the durable cannot be replaced quickly.

An important difference to Gollier [2003] is, however, that a small value of cashon-hand implies a small value of the durable stock and thus smaller losses. In fact the loss is negligibly small as $v$ approaches 0 . In this case market insurance serves no purpose so that the retention ratio also approaches 1 if cash-on-hand becomes 
sufficiently small. Moreover, the cost of insurance in terms of marginal utility of forgone non-durable consumption is high for small values of cash-on-hand.

Formally, the desirability of market insurance depends on the covariance of the marginal utility of non-durable consumption and the loss. The optimality condition (4) implies that for an endogenous loss

$$
u^{\prime}\left(c_{t}\right) \mu \eta \lambda v_{t+1}=\beta(1+r)\left[\eta \lambda v_{t+1} E_{t} u^{\prime}\left(c_{t+1}\right)+\operatorname{cov}\left(u^{\prime}\left(c_{t+1}\right), \eta I_{t} v_{t+1}\right)\right] .
$$

Market insurance is more attractive if the covariance is larger since in this case a loss implies a higher marginal utility of non-durable consumption $u^{\prime}\left(c_{t+1}\right)$. This can be seen heuristically from the equation above: a larger covariance (a larger righthand side of the equation) makes agents more willing to spend one more unit in insurance and forgo consumption in period $t$ so that the marginal utility $u^{\prime}\left(c_{t}\right)$ increases until the equation again holds with equality. As explained above the covariance is small for large values of cash-on-hand if the agent accumulates a substantial amount of risk-free assets (in this case a loss leaves the marginal utility of non-durable consumption essentially unchanged). Moreover, the covariance also decreases substantially as $v$ becomes negligibly small. ${ }^{5}$ This is illustrated in Fig. 2c which plots both the retention ratio and the covariance as a function of cash-on-hand (the scale of the covariance is displayed on the right). The covariance is calculated by setting $D_{t+1}=1$ but keeping all other policies at their previous optimal values. This is the counterfactual covariance between $u^{\prime}\left(c_{t+1}\right)$ and $\eta I_{t} v_{t+1}$ had the agent not chosen to insure himself in the next period.

Finally, in Fig. 2a-c we plot the first-order conditions (FOC) for the three choice variables $a_{t+1}, v_{t+1}$, and $D_{t+1}$ as a further check for the accurateness of our computations. Indeed, the figures show that the respective FOC is zero as soon as interior optima are attained. ${ }^{6}$

We use the policy functions to simulate the model for 1,000 periods. Figure 3 displays the results for the variables of interest for an arbitrary interval of 150 periods within the last 900 periods of the simulation in which the initial conditions are irrelevant. If no shock occurs, the consumer accumulates a substantial amount of the risk-free asset (up to $50 \%$ of disposable income in Fig. 3b). If a loss occurs these riskfree assets are used to adjust the durable stock close to its old level (see Fig. 3a), unless risk-free assets have been depleted by previous shocks and durable expenditure crowds out non-durable consumption. In this case the durable expenditure is smoothed over a number of periods (see Fig. 3e). This implies that durable consumption has spikes in periods after a durable loss occurs whereas non-durable consumption is quite smooth and changes only slightly in the aftermath of a shock as long as risk-free assets are sufficient to smooth out some of the durable loss (see Fig. 3d). The fall of the retention ratio in times with a small amount of risk-free assets is not enough to compensate for the lack of financial resources (see Fig. 3c). The retention rate

\footnotetext{
$\overline{5}$ Non-separable utility of durable and non-durable consumption does not change this qualitative insight as long as the variability of the marginal utility of non-durable consumption is higher for small values of cash-on-hand.

${ }^{6}$ Note that cash-in-hand $x_{t} \geq 1$ because labor income $y=1$. Thus, $v_{t+1}>0$ for all values of cash-in-hand for which we plot the policies so that the corresponding FOC always holds with equality.
} 
(a) Current Durable Stock v(t)

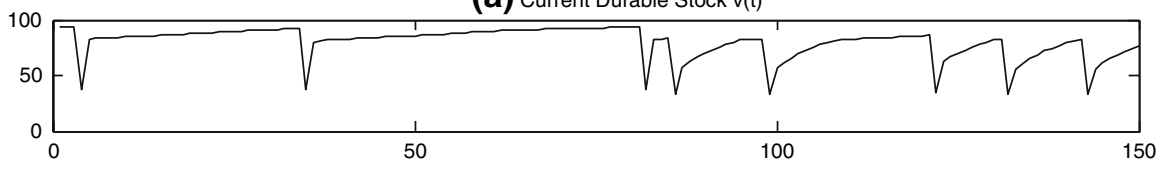

(b) Financial Assets a(t+1)

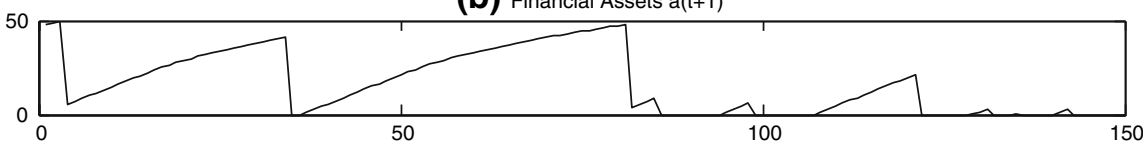

(c) Retention Ratio $\mathrm{D}(\mathrm{t})$

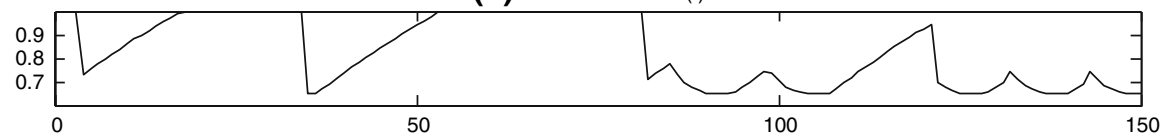

(d) Consumption Expenditure $c(t)$

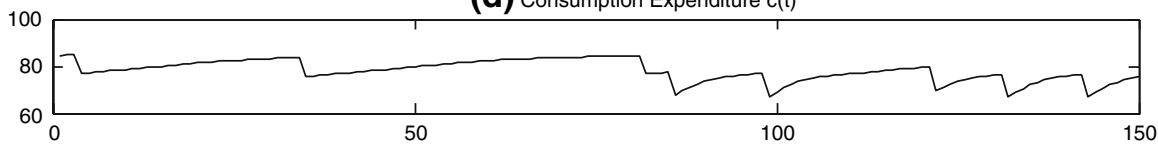

(e) Durable Expenditure $d(t)$

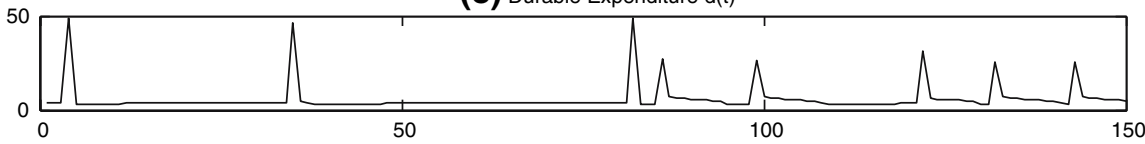

(f) Insurance Expenditure

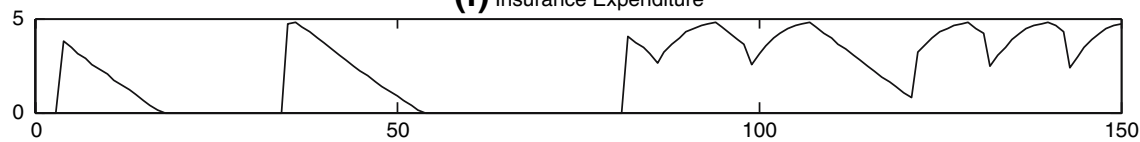

Fig. 3 Simulation of the main variables of interest for 150 quarters. Note: Simulations have been performed for 1,000 quarters of which the first 100 quarters have been discarded so that initial conditions do not matter. All variables but the retention ratio are in $\%$ of disposable income

fluctuates substantially between .6 in the aftermath of a shock when the agent is liquidity constrained, and 1 in periods in which the stock of risk-free assets is substantial. As a result also insurance expenditure fluctuates between $0 \%$ and $5 \%$ (see Fig. 3f). Rather short-time horizons of 15 quarters without a loss are sufficient to accumulate enough financial assets for market insurance to become irrelevant. Since time diversification across such periods is likely to matter for real-life consumer decision-making, we can expect our model to match average statistics observed in the US.

Table 2, column 1, displays the averages of the last 900 periods of the simulations for the stocks and flows. Moreover, we compute the relevant measures to be compared with the target statistics where as before we define disposable income as the sum of interest and labor income $i \equiv r a+y$ and convert flows to an annual frequency. In the benchmark case agents hold a durable stock that amounts to $80 \%$ of disposable income, durable consumption is $23 \%$ of total consumption and the insurance expenditure is $2.4 \%$ of disposable income. These values are in line 


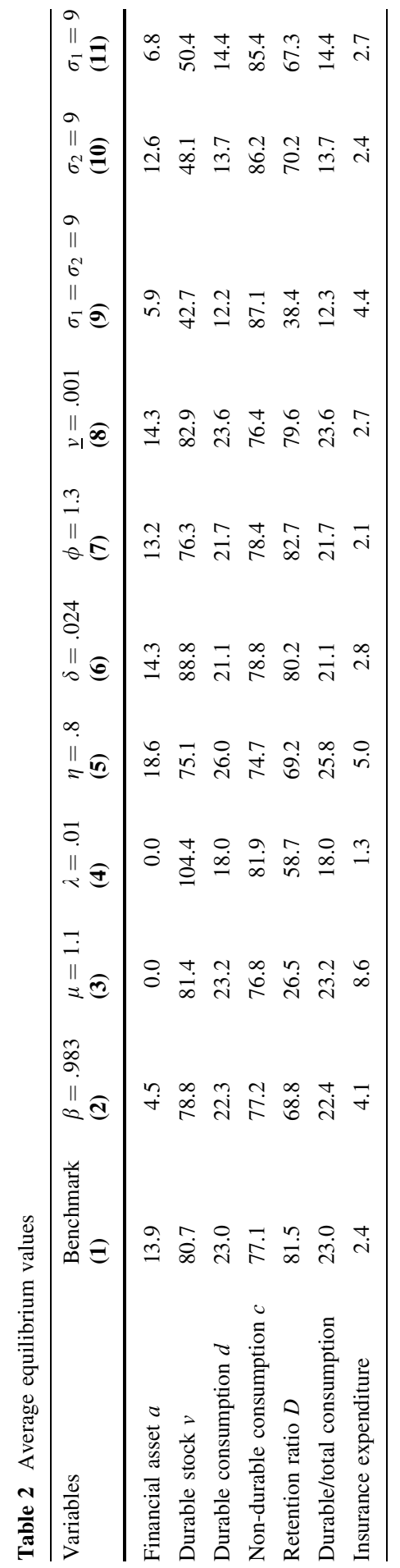


with our target statistics as we have chosen $\eta$ and $\varphi$ accordingly. Moreover, bufferstock saving is important since agents hold risk-free assets that amount to $14 \%$ of disposable income. However, the average retention ratio $D=.81$ is an order of magnitude larger than observed in real world insurance contracts (for example, as mentioned by Gollier [2003] insurance contracts for cars often have retention ratios of .025: a car with a value of $\$ 20,000$ would have a deductible of $\$ 500$ in a typical insurance contract; see also Drèze [1981]). Quantitatively, the retention ratio in our model is higher than in Gollier [2003] who finds $D=.63$ for similar parameter values. The difference is not surprising. Whereas in the model of Gollier the agent has only the choice between self-insurance with risk-free assets and market insurance, in our model the agent also can adjust the durable stock to manage the risk. This decreases the need for market insurance further.

We assess the welfare gains of granting the consumer access to market insurance in addition to the risk-free asset. We compute the value function for the restricted problem $V^{r}$ (.) without market insurance and compare it with the unrestricted value function $V\left(\right.$.) at the steady-state cash-on-hand of the restricted problem, $x^{r}$. We then perform the following thought experiment: how much additional cash-on-hand $x^{*}$ does the consumer need to receive in the restricted case, in order to be compensated for not having access to market insurance? Formally this can be computed as

$$
V^{r}\left(x^{r}+x^{*}\right)=V\left(x^{r}\right) .
$$

Note that the unrestricted value function $V($.$) is also evaluated at the steady state$ of the restricted problem because the welfare effect of market insurance includes the transition period to the new steady state. We find that market insurance is worth an additional $2.3 \%$ in the stock of cash-on-hand or, expressed in certainty-equivalent flows, an additional $0.12 \%$ flow of non-durable consumption if we hold the durable stock constant at its steady-state value $\widetilde{v}\left(x^{r}\right)$. Since the retention ratio in the unrestricted equilibrium is higher in our model than in Gollier [2003], it is not surprising that our welfare effect is substantially lower than the $0.66 \%$ increase of non-durable consumption reported in Gollier [2003], Table 1, as mentioned above), this welfare effect of market insurance is substantially lower than the $0.66 \%$ increase of non-durable consumption in Gollier [2003], Table 1. Thus, allowing for an endogenous risk not only matters for the qualitative shape of the policy function for the retention ratio but also for the quantitative importance of market insurance.

\subsubsection{Sensitivity analysis}

We now provide a sensitivity analysis for different parameter values in order to investigate whether the result of a high retention ratio is robust. We change one parameter at a time, displaying the new changed parameter value at the top of each column in Table 2.

In column 2 we decrease the discount factor (to an annual value of .935). This increases the spread between the discount rate and the interest rate and makes buffer-stock saving more costly so that the stock of risk-free assets falls to $4.5 \%$ of disposable income. Market insurance instead becomes more attractive and the 
retention ratio falls to $D=.69$. More impatience also makes durable consumption less attractive since utility can only be derived from it next period. However, the durable stock falls only slightly so that insurance expenditure increases to $4.1 \%$ of disposable income. Qualitatively similar is the effect of lowering the cost of insurance in column 3. An unrealistically low loading factor of $\mu=1.1$ is necessary however, in order to lower the retention ratio to more plausible values, $D=.27$. Moreover, in this case, the insurance expenditure of $8.6 \%$ of disposable income is much above its empirically observed value.

In columns 4 and 5 we lower the probability of the loss and increase the size of the loss, respectively. Both make market insurance more attractive. A small probability of the loss implies that insurance premiums become relatively cheaper (although market insurance is actuarially unfair this matters less for premiums if the probability of the loss is small). Letting the probability of a loss fall to $\lambda=.01$ implies a retention ratio $D=.59$, and increases the durable stock and thus the risk exposure. Although market insurance becomes more attractive so that the agent no longer holds risk-free assets, the much lower probability of the loss decreases insurance premiums so that insurance expenditure falls to $1.3 \%$ of disposable income. Instead, increasing the size of the loss from $60 \%$ of the durable stock to $80 \%$, implies a lower retention rate $D=.69$, increases insurance premiums and thus insurance expenditure to $5 \%$, and the stock of risk-free assets to $18 \%$ of disposable income. Both non-durable consumption and the durable stock are smaller.

In column 6 we lower the depreciation rate to an annual value of $10 \%$ (from previously $15 \%$ ). This makes it less costly to accumulate the durable so that the durable stock increases. Since this also increases the exposure, the buffer stock of risk-free assets slightly increases whereas the retention ratio falls only slightly from $D=.81$ to $D=.80$.

We also experimented with a monthly instead of quarterly frequency (results are not reported in Table 2). A shorter frequency decreases the consequences of a durable loss in marginal-utility terms since agents can readjust their durable stock more quickly. This increases the retention rate even further to $D=.88 .^{7}$ Furthermore, relaxing the liquidity constraint so that agents can borrow makes little difference since the stock of cash-on-hand adjusts downward and the wealth effect resulting from interest payments is quantitatively small.

We now investigate in columns 7-11 whether changes in the parameters of the utility function can achieve more realistic values for the retention ratio. In columns 7 and 8 , we change the marginal utility the agent derives from durables. A smaller $\phi=1.3$ implies a lower marginal utility for the durable, ceteris paribus, so that the durable stock and the exposure is smaller, the retention rate increases slightly and the insurance expenditure falls. Analogously, a smaller $\underline{v}=.001$, increases the marginal utility which has the opposite effect. Note that setting $\underline{v}$ to a negligibly small value is innocuous quantitatively. This parameter does not play a big role in our numerical results.

Finally, we experiment with higher values of risk aversion. We first symmetrically set $\sigma_{1}=\sigma_{2}=9$ in column 9 , before we change one parameter at a time in

\footnotetext{
${ }^{7}$ A shorter frequency also changes the intertemporal elasticity of substitution and thus the optimal ratio of non-durable to durable consumption.
} 
columns 10 and 11, respectively. Not surprisingly higher risk aversion decreases the retention ratio and the durable stock. Market insurance becomes relatively more attractive as the buffer stock of risk-free assets falls. Of course, substitution away from the durable stock towards non-durable consumption would even occur in the certainty case. To provide a heuristic argument, let us assume for simplicity that $\delta=1, \underline{v}=0$ and no durable loss in which case the first-order condition (3) implies

$$
\frac{c}{v}=\left(\frac{1}{\beta \phi}\right)^{\frac{1}{\sigma}} \text {. }
$$

Since $\beta \phi>1$ for the used parameters, a larger $\sigma=\sigma_{1}=\sigma_{2}$ implies that $c / v$ increases. Moreover, a higher $\sigma$ also implies a lower intertemporal elasticity of substitution (which we cannot disentangle from risk-aversion using a CRRA utility function). Thus, one could expect that a smaller planned durable stock is chosen to lower intertemporal fluctuations (because the loss increases in the size of the durable stock). However, the simulations reveal that the realized durable stock is adjusted relatively more quickly to its previous level in the aftermath of a shock so that its average value increases, ceteris paribus. Comparing column 9 in which $\sigma_{1}=\sigma_{2}=9$ and column 11 in which $\sigma_{1}=9$ and $\sigma_{2}=2$, with our benchmark of $\sigma_{1}=\sigma_{2}=2$ suggests that quantitatively the intertemporal elasticity of substitution of the durable alone is not crucial for a sizeable drop of the average durable stock.

More interestingly, our computations show that both $\sigma_{1}$ and $\sigma_{2}$ need to increase for the retention rate to fall substantially to $D=.38$ in column 9 . Nonetheless, quantitatively even a sizeable increase in risk aversion to $\sigma_{1}=\sigma_{2}=9$ is not enough to generate retention ratios that are consistent with the low levels observed in realworld insurance contracts.

For commonly used values of risk aversion, a simple dynamic neoclassical model does not manage to replicate the low retention ratios observed in real-world data. This "insurance" puzzle is reminiscent of the well-known equity premium puzzle [see Mehra and Prescott, 1985; Gollier, 2003]. In reality, agents are "puzzlingly" unwilling to invest in risky assets (notwithstanding their much higher expected returns) similarly as they are unwilling to bear more exposure of the durable stock. However, there are some important differences in our model since agents derive utility from the risky durable stock (which makes them hold the durable in the first place) and agents can insure the risk of the durable in the market.

We now check the robustness of our result further for two extensions which can be expected to increase the importance of market insurance in our model. We first relax the assumption of an exogenous borrowing constraint and allow agents to use their secured durables as collateral. This is in line with the empirical observation that mortgage lenders often require agents to insure their property in order to secure the collateral. Second, we relax the assumption of a certain labor income. We explore how income risk as a source of background risk affects the agent's insurance decision. An alternative would be to allow for persistent shocks to the durable which are likely to make buffer-stock saving a less perfect substitute for market insurance. Since i.i.d. shocks seem a realistic assumption for most property 
Table 3 Endogenous collateral constraint

\begin{tabular}{llcc}
\hline Variables & $\begin{array}{l}\text { Benchmark } \\
(\mathbf{1})\end{array}$ & $\begin{array}{l}\text { Collateral } \\
(\mathbf{2})\end{array}$ & $\begin{array}{l}\text { Collateral, } \eta=0.2 \\
(\mathbf{3})\end{array}$ \\
\hline Financial asset $a$ & 13.9 & -49.4 & -86.6 \\
Durable stock $v$ & 80.7 & 82.2 & 104.2 \\
Durable consumption $d$ & 23.0 & 20.9 & 19.1 \\
Non-durable consumption $c$ & 77.1 & 76.0 & 79.2 \\
Retention ratio $D$ & 81.5 & 52.0 & 62.5 \\
Durable/total consumption & 23.0 & 21.6 & 19.5 \\
Insurance expenditure & 2.4 & 6.4 & 2.1 \\
\hline
\end{tabular}

and liability damages associated with durables, however, we decided to allow for persistent labor income shocks in our model.

\subsubsection{Collateral loans}

If agents can use their secured durable stock as collateral, insurance has the additional role of securing more of the durable stock and thus relaxing the borrowing constraint. We model this extension by changing the constraint $a_{s} \geq 0$ to

$$
(1+r) a_{s}+\left(1-\delta-D_{s} \eta\right) v_{s} \geq 0, \quad s \geq t+1 .
$$

The constraint implies that the agent can take on financial debt as long as this debt and its interest are secured by durable collateral. Only the part of the durable stock, however, which is not exposed to risk can be used as collateral. Note that how much the agent can borrow now depends on the consumer's choices of $D$ and $v$. Insurance, a lower retention rate $D$, relaxes the collateral constraint by increasing the part of the durable stock which can be used as collateral. This creates an additional insurance motive which is frequently observed in reality: banks often require consumers to insure their property if consumers apply for a mortgage. This additional insurance motive is important for low values of cash-on-hand. Hence, the non-monotonicity of the retention ratio as a function of cash-on-hand vanishes in our calibration so that the retention ratio is an increasing function of cash-on-hand in the computations which we present now.

Table 3 displays the results. Column 1 repeats the benchmark result to facilitate comparisons. In column 2 , we introduce the new constraint without changing the parameters of the benchmark case. The main difference, compared with the benchmark case, is that the agents hold more financial debt and choose a lower retention ratio of 0.52 . Since also the durable stock increases slightly, the insurance expenditure is three times higher than in the benchmark case. In order to match the observed insurance expenditure of $2 \%$ of disposable income, we decrease the size of the loss to $\eta=0.2$ in column 3 . The retention ratio is then 0.63 which is still much lower than in the benchmark case. Compared with the values of the retention ratio observed in reality, however, these values remain an order of magnitude too high. 
In order to quantify the importance of market insurance with endogenous collateral constraints, we perform the same thought experiment as above. We compare the value function of Table 3, column 3, with the counterfactual value function and steady state if we restrict the consumer to have access to the financial asset but not to market insurance. We evaluate both value functions at the steady state of the restricted problem so that our comparison includes the transition to the new steady state. We find that a consumer would be indifferent between gaining access to market insurance or a $1.3 \%$ higher steady-state non-durable consumption flow. Thus, market insurance is 10 times as important compared with the benchmark case.

\subsubsection{Permanent income risk}

We now return to our benchmark model with the exogenous borrowing limit and allow for an additional source of background risk. We assume that labor income is risky and that this risk and the durable risk are independently distributed. Labor income now follows the process

$$
y_{t+1}=y_{t} \varepsilon_{t}
$$

where $\varepsilon_{t}$ has the support $\left\{\varepsilon_{b}, 1, \varepsilon_{g}\right\}$ with the corresponding probabilities $\left\{p_{b}, 1-p_{g}-p_{b}, p_{g}\right\}$. In order to ensure comparability with the previous results we do not allow for a change in the mean so that the expected value of income is 1 . Moreover, we assume that the standard deviation of permanent income shocks is $.1 \%$ per year based on estimations for the PSID in the US [see Carroll, 1997]. These restrictions on the first and second moment allow us to retrieve $p_{g}$ and $p_{b}$ once we have chosen $\varepsilon_{g}=1.1$ and $\varepsilon_{b}=.75$ : a permanent good shock increases labor income by $10 \%$ whereas a bad shock decreases it by $25 \%$. These are quite sizeable shocks which help us to find out whether empirically plausible permanent income risk can make market insurance more important.

All other parameters are as in the benchmark case but for $\underline{v}=0$. In this case, we can exploit that the value function is homogenous of degree $1-\sigma, \sigma=\sigma_{1}=\sigma_{2}$, so that permanent income shocks do not add another state variable to the value function [see, for example, Haliassos and Michaelides, 2001]. The independence of the two risks allows us to write

$$
E V\left(x_{t}, \widetilde{v}_{t}, y_{t}\right)=E_{l} E_{y \mid l} V\left(x_{t}, \widetilde{v}_{t}, y_{t}\right)
$$

and homogeneity then implies

$$
E_{y \mid l} V\left(x_{t}, \widetilde{v}_{t}, y_{t}\right)=E_{y \mid l}\left[\varepsilon_{t}^{1-\sigma} \widetilde{V}\left(x_{t}, \widetilde{v}_{t}\right)\right]
$$

which simplifies the computations substantially.

Before we turn to the results let us mention that labor income risk will induce buffer-stock saving even without any durable risk. This has been shown in the seminal papers on precautionary savings in models with non-durable consumption 
Table 4 Permanent labor income risk

\begin{tabular}{|c|c|c|c|}
\hline Variables & $\begin{array}{l}\text { Benchmark, } \underline{v}=0, s d=0 \\
\text { (1) }\end{array}$ & $\begin{array}{l}s d=.1 \% \\
(2)\end{array}$ & $\begin{array}{l}s d=10 \% \\
\text { (3) }\end{array}$ \\
\hline Financial asset $a$ & 14.39 & 14.44 & 19.77 \\
\hline Durable stock $v$ & 82.87 & 82.91 & 83.68 \\
\hline Durable consumption $d$ & 23.60 & 23.61 & 23.85 \\
\hline Non-durable consumption $c$ & 76.43 & 76.42 & 76.39 \\
\hline Retention ratio $D$ & 79.67 & 79.72 & 84.39 \\
\hline Durable/total consumption & 23.59 & 23.60 & 23.79 \\
\hline Insurance expenditure & 2.69 & 2.67 & 2.03 \\
\hline
\end{tabular}

Note: $s d$ : standard deviation of permanent income

and liquidity constraints (see the partial-equilibrium model of Deaton [1991], and the general-equilibrium model with heterogenous agents of Aiyagari [1994]). Diaz and Luengo-Prado [2005] and Gruber and Martin [2003] have extended this work by adding durable goods with adjustment costs to the model. They find that it is ambiguous in general whether the importance of the precautionary motive increases in dynamic models with durable and non-durable consumption. In these models, durables let current utility depend on past expenditure so that the precautionary savings motive is smaller ceteris paribus. An important difference in our model is that the risk associated with the durable stock strengthens the precautionary motive for the durable good (see also the analytic approximation of the policy functions in Appendix A, for the special case in which financial wealth is abundant).

The results are summarized in Table 4. In the first column we display the equilibrium values for our benchmark case without permanent labor income risk but with $\underline{v}=0$. In Table 4, column 2 we add permanent labor income risk with a standard deviation of $.1 \%$. This leaves the quantitative results nearly unchanged. Finally, we increase the permanent income risk to $10 \%$ in column 3 . This increases the buffer stock of risk-free assets to $20 \%$ of disposable income and slightly reduces non-durable consumption. The higher level of risk-free assets makes market insurance even less important so that the retention ratio increases to .84 . The durable stock increases slightly but insurance expenditure falls due to the lower retention ratio. Thus, in the new steady state with a larger stock of durables and risk-free assets, market insurance is even less important although ceteris paribus insurance payments are more valuable if the bad income shock is accompanied by a loss of the durable.

\subsection{The closed economy}

We have shown so far that a dynamic neoclassical model of market insurance has difficulties to match realistic values of retention ratios even if insurance endogenously relaxes the collateral constraint or agents face additional uninsurable permanent labor income risk. We now briefly mention that this conclusion does not change if we allow for an endogenous interest rate in the closed economy. This is 
important because buffer-stock saving becomes more relevant compared with market insurance if the difference between the discount and interest rate is small. This difference measures the cost of saving for the impatient agent and we now determine how big this cost has to be if the interest rate is market clearing.

In order to analyze market insurance in the closed economy we have to adapt our maximization problem slightly. In our model insurance companies make profits since they charge a mark-up and in the closed economy these profits are part of the consumer's budget constraint. The "new" budget constraint for the average agent reads

$$
\begin{aligned}
a_{t+1}= & (1+r) a_{t}+y_{t}+\overbrace{\left(1-D_{t}\right) E l_{t}}^{\text {insurance claim }} \\
& -c_{t}-d_{t}-\overbrace{\frac{\overbrace{1}^{\mu}}{1+r}\left(1-D_{t+1}\right) E l_{t+1}}^{\text {insurance premium }}+\overbrace{\pi_{t}}^{\text {insurance profits }}
\end{aligned}
$$

where

$$
\pi_{t}=(1+r) \frac{\mu}{1+r}\left(1-D_{t-1}\right) E l_{t}-\left(1-D_{t-1}\right) E l_{t}
$$

Note that we use the law of large numbers so that the average loss over a large cross-section of individuals is equal to the expected value.

Using this expression for $\pi_{t}$ in the budget constraint and defining

$$
b_{t} \equiv \frac{\mu}{1+r}\left(1-D_{t-1}\right) E l_{t}
$$

we get

$$
a_{t+1}+b_{t+1}=(1+r)\left(a_{t}+b_{t}\right)+y_{t}-c_{t}-d_{t} .
$$

Aggregate assets in the economy, $a_{t}+b_{t}$, are risk-free assets $a$ and the insurance premiums which the insurers invest at interest rate $r$. With this slight modification, we can solve the model numerically as before for a given interest rate $r$. This will give us the aggregate "supply" of capital.

In order to find out which interest rate is market clearing, we specify a standard Cobb-Douglas production function with constant returns and a capital-labor ratio $k$. In intensive form this function is given by

$$
f(k)=A k^{\alpha}
$$

with $\alpha=$.36. We normalize with the endogenously computed wage income and exploit the homogeneity of the value function as before. Assuming that factors are paid their marginal product then implies a "demand" for capital ${ }^{8}$

\footnotetext{
${ }_{8}$ The first-order conditions are $A \alpha k^{\alpha-1}=r+\xi$ and $A(1-\alpha) k^{\alpha}=w$. Dividing both conditions and setting $w=1$ results in the expression in the text.
} 


$$
k=\frac{\alpha}{(1-\alpha)(r+\xi)}
$$

where $\xi$ is the physical depreciation of capital and we assume an annual depreciation rate of $\xi=.08$. For each "supply" of assets computed for given $r$, we can use the equation for the "demand" for capital to update the interest rate and restart the algorithm until convergence. This method is essentially as in Aiyagari [1994]. It turns out that the interest rate $r$ which would clear the market for our parameter values is so close to the discount rate that there is no role for market insurance at all. For example, at an annual interest rate of $r=.048$ (which is close to the annual discount rate of $5.25 \%$ in our model) the supply for capital in our model is only one quarter of the demand. Since we know from Aiyagari [1994], that the assets held by the agent (capital "supply") approach infinity as the interest gets ever closer to the discount rate from below, the market clearing interest rate is even higher. We find that already at an interest rate of $r=.048$, the retention rate is .9961 so that market insurance is negligible.

The small quantitative role of market insurance remained robust for many alternative parameter combinations that we have tried. Recalibrating the parameters $\eta$ and $\varphi$ (which were chosen above to match target statistics for $r=.01$ ) did not make market insurance much more important. As can be seen in the sensitivity analysis of Table 2, increasing the size of the loss to .8 (column 5) does not reduce the retention rate enough while increasing the stock of risk-free assets; and choosing a larger $\varphi$ to increase the stock of risk-free assets and to reduce the retention ratio would imply unrealistic spending patterns of durable compared with non-durable consumption (column 7).

\section{Conclusion}

We set up and solve numerically a dynamic neoclassical model of market insurance in which agents derive utility from a durable and non-durable good. The durable good is exposed to risk and can be insured. We analyze the role of market insurance if agents also have access to a risk-free asset. We provide intuition for our results using first-order conditions, and a second-order approximation for the special case of abundant financial wealth.

We find that the retention ratio (the fraction of the durable that is not insured) can be a non-monotonic function of cash-on-hand. This differs from previous results by Gollier [2003] and can be explained with the endogenous loss associated with the durable stock. Calibrating our model to the US economy, we find that the average retention ratio is an order of magnitude larger than observed in reality. This result remains unchanged if we allow consumers to use secured durables as collateral, add permanent labor income risk or allow for endogenous interest rates. This "insurance" puzzle is reminiscent of the equity-premium puzzle although our model is different in a number of respects. 
Future research could relax some of the simplifying assumptions in our model such as the perfect divisibility of durable goods, the separability of the utility function or introduce adjustment costs for durables in order to be more confident about the results. One could also allow for more institutional detail on insurance contracts. Regulation on insurance contracts might restrict agents in their choice of retention ratios although in reality mandatory insurance is hard to enforce [see Smith and Wright, 1992]. Finally, more complex models with life-cycle patterns of durable and non-durable consumption might help to increase the importance of market insurance. If agents accumulate durables early in life to relax collateral constraints [see Fernandez-Villaverde and Krueger, 2002], this makes a loss of the durable especially costly so that market insurance might become more desirable.

\section{Appendices}

Appendix A: Approximation of the policy functions for abundant financial wealth

The model presented in the text does not have a closed-form solution in general. We present the results of a second-order approximation of the policy functions and laws of motion to develop some intuition (the numerical solution is described in Appendix B). We do the approximation for the model with two sources of risk in labor income and the durable stock, keeping the interest rate constant. The main point of this exercise is to show that in our model precautionary motives are important even if agents own abundant financial wealth because durables are a state variable and directly enter the utility function.

To approximate the solution we employ the perturbation method which is explained in detail in Schmitt-Grohé and Uribe [2001] using the Euler equations (2)-(4) and the two laws of motion for $a$ and $v$. We first provide the solution of the approximation and some intuition before we get to the derivation. Because we do allow the state variables to be at interior optima only, for the purpose of the approximation, the results simplify considerably and can be used to develop intuition on the mechanics of the model. That is, we assume that the agent's stock of risk-free assets is sufficient to buffer income shocks and allow the durable stock to return to the steady state after one period through the appropriate durable investment if a loss occurs. The policy functions can then be approximated by

$$
\begin{gathered}
c=c_{s s} \\
d=d_{s s}-(1-\delta)\left(v-v_{s s}\right)+\frac{1}{2} \gamma \sigma_{l}^{2} \\
D=D_{s s} \\
a=a_{s s}+(1+r)\left(a-a_{s s}\right)-(1-\delta)\left(v-v_{s s}\right)-\frac{1}{2} \gamma \sigma_{l}^{2} \\
v=v_{s s}+\frac{1}{2} \gamma \sigma_{l}^{2},
\end{gathered}
$$


where

$$
\gamma \equiv-\frac{w^{\prime \prime \prime}\left(v_{s s}\right)}{w^{\prime \prime}\left(v_{s s}\right)} .
$$

The steady state is obtained solving the model without uncertainty. Hence, no market insurance is demanded, i.e., $D_{s s}=1$. Note that the steady state of risk-free assets $a_{s s}$ is such that the steady state non-durable consumption $c_{s s}$ and durable investment $d_{s s}=\delta v_{s s}$ are feasible.

We also derived the approximation for the more general case in which households do not have abundant financial wealth. However, expressions become very messy so that they do not help much to develop intuition on the mechanics of the model. Hence, we focus on this special but important case. We now discuss the solution in detail.

\section{First-order deviations}

The first-order deviations of $a$ or $v$ from the steady state do not affect non-durable consumption or the durable stock. Shocks occurring to the durable stock are offset after one period (net of the depreciation rate) by durable investment which is fully financed by risk-free assets. Shocks occurring to risk-free assets do not result in any reaction of the controls but only change risk-free assets by the same amount and the interest income.

\section{Second-order deviations and variances}

Neither the second-order deviations of risk-free assets from the steady state nor the one of the durable stock do matter if agents have abundant financial wealth. Instead, the variance of the durable shock turns out to be important whereas the variance of income does not affect the solution. The asymmetric effect of the variances is resulting from the model's structure: since $v$ enters the utility function, the fluctuations of $v$ directly result in variation of utility whereas this is not the case for fluctuations of $a$.

The importance of the variance of the loss depends on $\gamma$, a measure of prudence with respect to the durable stock, $-w^{\prime \prime \prime}\left(v_{s s}\right) / w^{\prime \prime}\left(v_{s s}\right)$, defined according to Kimball [1990]. Since agents derive utility from the durable stock, they invest more into durables if durables are more exposed to risk. Thus, the durable stock rises and financial wealth falls. This is in contrast to investment behavior for risky assets from which agents do not directly derive utility but only indirectly since more assets afford more units of non-durable consumption. We now present the derivation of the approximation in some detail.

\section{Derivation}

Consistent with the notation used in Schmitt-Grohé and Uribe [2001], we define the matrix $F$ as 


$$
F \equiv\left[\begin{array}{c}
u^{\prime}\left(c_{t}\right)-\beta(1+r) E_{t} u^{\prime}\left(c_{t+1}\right) \\
u^{\prime}\left(c_{t}\right)-\beta\left[(1-\delta) E_{t} u^{\prime}\left(c_{t+1}\right)+\phi E_{t} w^{\prime}\left(\widetilde{v}_{t+1}\right)\right] \\
\beta(1+r) E_{t}\left\{u^{\prime}\left(c_{t+1}\right) l_{t+1}\right\}-u^{\prime}\left(c_{t}\right) \mu E l_{t+1} \\
a_{t+1}-(1+r) a_{t}+c_{t}+d_{t}+\frac{\mu}{1+r}\left(1-D_{t+1}\right) E l_{t+1}-\left(1-D_{t}\right) l_{t}-y_{t} \\
v_{t+1}-(1-\delta) v_{t}-d_{t}+l_{t}
\end{array}\right]
$$

where $F=0$. We define the controls as $\zeta=(c, d, D)^{\prime}$ and the state variables as $x=(a, v)^{\prime}$. The shocks can be rewritten as

$$
l=m_{l}+\sigma_{l} \varepsilon_{l}
$$

and

$$
y=m_{y}+\sigma_{y} \varepsilon_{y}
$$

where $\varepsilon_{i} \sim N(0,1), i=l, y$ and $m_{y}=E y, m_{l}=E l$. The shocks are assumed to be i.i.d.

We know that the solution will take the form $\zeta_{t}=g\left(x_{t}^{\prime}, \sigma^{\prime}\right)$ and $x_{t+1}=h\left(x_{t}^{\prime}, \sigma^{\prime}\right)+\eta \varepsilon_{t}$, where $\varepsilon_{t}=\left(\varepsilon_{l t}, \varepsilon_{y t}\right)^{\prime}$. The $2 \times 2$ matrix $\eta$ and $\sigma=\left(\sigma_{y}, \sigma_{l}\right)^{\prime}$ are known. In our model

$$
\eta=\left[\begin{array}{cc}
(1-D) \sigma_{l} & \sigma_{y} \\
-\sigma_{l} & 0
\end{array}\right]
$$

Note that $y_{t}$ and $l_{t}$ are i.i.d. distributed shocks and we take $D$ (the first element of the matrix $\eta$ ) as a given parameter. This simplifies the algebra since we do not have to consider 3 state variables and is innocuous since we will focus on the case of abundant financial wealth. To perform a second-order approximation, first and second derivatives of the functions $g($.) and $h($.) need to be determined. As explained in more detail in Schmitt-Grohé and Uribe [2001] this is done by taking first and second derivatives of $F$ with respect to $x$ and exploiting the fact that these derivatives are 0 .

We find that

$$
F_{x}=\left[\begin{array}{c}
-\beta(1+r) E_{t} u^{\prime \prime}\left(c_{t+1}\right)\left[g_{a}^{c} h_{a}^{a}+g_{v}^{c} h_{a}^{v}\right]+u^{\prime \prime}\left(c_{t}\right) g_{a}^{c} \\
-\beta(1-\delta) E_{t} u^{\prime \prime}\left(c_{t+1}\right)\left[g_{a}^{c} h_{a}^{a}+g_{v}^{c} h_{a}^{v}\right]+u^{\prime \prime}\left(c_{t}\right) g_{a}^{c}-\beta \phi E_{t} w^{\prime \prime}\left(\widetilde{v}_{t+1}\right) h_{a}^{v} \\
\frac{\partial F(3,1)}{\partial c_{t+1}}\left[g_{a}^{c} h_{a}^{a}+g_{v}^{c} h_{a}^{v}\right]-\frac{\mu}{1+r} E l_{t+1} u^{\prime \prime}\left(c_{t}\right) g_{a}^{c}+\frac{\partial F(3,1)}{\partial D_{t+1}} g_{a}^{D} \\
g_{a}^{c}+g_{a}^{d}-\frac{\mu}{1+r} E l_{t+1} g_{a}^{D}+h_{a}^{a}-(1+r) \\
-g_{a}^{d}+h_{a}^{v} \\
-\beta(1+r) E_{t} u^{\prime \prime}\left(c_{t+1}\right)\left[g_{a}^{c} h_{v}^{a}+g_{v}^{c} h_{v}^{v}\right]+u^{\prime \prime}\left(c_{t}\right) g_{v}^{c} \\
-\beta(1-\delta) E_{t} u^{\prime \prime}\left(c_{t+1}\right)\left[g_{a}^{c} h_{v}^{a}+g_{v}^{c} h_{v}^{v}\right]+u^{\prime \prime}\left(c_{t}\right) g_{v}^{c}-\beta \phi E_{t} w^{\prime \prime}\left(\widetilde{v}_{t+1}\right) h_{v}^{v} \\
\frac{\partial F(3,1)}{\partial D_{t+1}}\left[g_{a}^{c} h_{v}^{a}+g_{v}^{c} h_{v}^{v}\right]-\frac{\mu}{1+r} E l_{t+1} u^{\prime \prime}\left(c_{t}\right) g_{v}^{c}+\frac{\partial F(3,1)}{\partial D_{t+1}} g_{v}^{D} \\
g_{v}^{c}+g_{v}^{d}-\frac{\mu}{1+r} E l_{t+1} g_{v}^{D}+h_{v}^{a} \\
-g_{v}^{d}+h_{v}^{v}-(1-\delta)
\end{array}\right]
$$


where derivatives of $F$ with respect to $a$ are in rows 1-5 and derivatives with respect to $v$ are in rows $6-10$. The notation $g_{a}^{c}$ denotes the derivative of non-durable consumption $c$ with respect to $a$ and $F(3,1)$ is the element in the third row and first column of $F$. Expressions for $\frac{\partial F(3,1)}{\partial c_{t+1}}$ and $\frac{\partial F(3,1)}{\partial D_{t+1}}$ can be derived using the fact that $E a b=E a E b+\operatorname{cov}(a, b)$, but are lengthy so that we use shorthand notation. $F_{x}$ is a system of 10 equations in 10 unknowns $g_{j}^{i}, h_{j}^{k}$ with $i=c, d, D ; j=a, v$ and $k=a, v$.

It turns out that one solution of the system of equations is

$$
\begin{aligned}
& g_{a}^{c}=g_{v}^{c}=g_{a}^{d}=g_{a}^{D}=g_{v}^{D}=h_{a}^{v}=h_{v}^{v}=0, \\
& h_{a}^{a}=1+r, \\
& g_{v}^{d}=-(1-\delta), \\
& h_{v}^{a}=1-\delta .
\end{aligned}
$$

This is the case of abundant financial wealth when $D=D_{s s}$ and $c=c_{s s}$. The solution for the general case is messy and does not add to the intuition.

We calculate $F_{x x}$ which gives us 20 equations to determine 20 second-order derivatives. Using that some of the first-order derivatives are zero, we get that

$$
F_{x a}=\left[\begin{array}{c}
-\beta(1+r) E_{t} u^{\prime \prime}\left(c_{t+1}\right) g_{a a}^{c}\left(h_{a}^{a}\right)^{2}+u^{\prime \prime}\left(c_{t}\right) g_{a a}^{c} \\
-\beta(1-\delta) E_{t} u^{\prime \prime}\left(c_{t+1}\right) g_{a a}^{c}\left(h_{a}^{a}\right)^{2}+u^{\prime \prime}\left(c_{t}\right) g_{a a}^{c}-\beta \phi E_{t} w^{\prime \prime}\left(\widetilde{v}_{t+1}\right) h_{a a}^{v} \\
\frac{\partial F(3,1)}{\partial c_{t+1}} g_{a a}^{c}\left(h_{a}^{a}\right)^{2}-\frac{\mu}{1+r} E l_{t+1} u^{\prime \prime}\left(c_{t}\right) g_{a a}^{c}+\frac{\partial F(3,1)}{\partial D_{t+1}} g_{a a}^{D} \\
g_{a a}^{c}+g_{a a}^{d}-\frac{\mu}{1+r} E l_{t+1} g_{a a}^{D}+h_{a a}^{a} \\
-g_{a a}^{d}+h_{a a}^{v} \\
-\beta(1+r) E_{t} u^{\prime \prime}\left(c_{t+1}\right) g_{a a}^{c} h_{a}^{a} h_{v}^{a}+u^{\prime \prime}\left(c_{t}\right) g_{v a}^{c} \\
-\beta(1-\delta) E_{t} u^{\prime \prime}\left(c_{t+1}\right) g_{a a}^{c} h_{a}^{a} h_{v}^{a}+u^{\prime \prime}\left(c_{t}\right) g_{v a}^{c}-\beta \phi E_{t} w^{\prime \prime}\left(\widetilde{v}_{t+1}\right) h_{v a}^{v} \\
\frac{\partial F(3,1)}{\partial c_{t+1}} g_{a a}^{c} h_{a}^{a} h_{v}^{a}-\frac{\mu}{1+r} E l_{t+1} u^{\prime \prime}\left(c_{t}\right) g_{v a}^{c}+\frac{\partial F(3,1)}{\partial D_{t}} g_{v a}^{D} \\
g_{v a}^{c}+g_{v a}^{d}-\frac{\mu}{1+r} E l_{t+1} g_{v a}^{D}+h_{v a}^{a} \\
-g_{v a}^{d}+h_{v a}^{v}
\end{array}\right]
$$

for the derivatives with respect to $a a$ in rows $1-5$ and derivatives with respect to $v a$ in rows 6-10 and

$$
F_{x v}=\left[\begin{array}{c}
-\beta(1+r) E_{t} u^{\prime \prime}\left(c_{t+1}\right) g_{a v}^{c}\left(h_{v}^{a}\right)^{2}+u^{\prime \prime}\left(c_{t}\right) g_{v v}^{c} \\
-\beta(1-\delta) E_{t} u^{\prime \prime}\left(c_{t+1}\right) g_{a v}^{c}\left(h_{v}^{a}\right)^{2}+u^{\prime \prime}\left(c_{t}\right) g_{v v}^{c}-\beta \phi E_{t} w^{\prime \prime}\left(\widetilde{v}_{t+1}\right) h_{v v}^{v} \\
\frac{\partial F(3,1)}{\partial c_{t+1}} g_{a v}^{c}\left(h_{v}^{a}\right)^{2}-\frac{\mu}{1+r} E l_{t+1} u^{\prime \prime}\left(c_{t}\right) g_{v v}^{c}+\frac{\partial F(3,1)}{\partial D_{t+1}} g_{v v}^{D} \\
g_{v v}^{c}+g_{v v}^{d}-\frac{\mu}{1+r} E l_{t+1} g_{v v}^{D}+h_{v v}^{a} \\
-g_{v v}^{d}+h_{v v}^{v} \\
-\beta(1+r) E_{t} u^{\prime \prime}\left(c_{t+1}\right) g_{a v}^{c} h_{v}^{a} h_{a}^{a}+u^{\prime \prime}\left(c_{t}\right) g_{a v}^{c} \\
-\beta(1-\delta) E_{t} u^{\prime \prime}\left(c_{t+1}\right) g_{a v}^{c} h_{v}^{a} h_{a}^{a}+u^{\prime \prime}\left(c_{t}\right) g_{a v}^{c}-\beta \phi E_{t} w^{\prime \prime}\left(\widetilde{v}_{t+1}\right) h_{a v}^{v} \\
\frac{\partial F(3,1)}{\partial c_{t+1}} g_{a v}^{c} h_{v}^{a} h_{a}^{a}-\frac{\mu}{1+r} E l_{t+1} u^{\prime \prime}\left(c_{t}\right) g_{a v}^{c}+\frac{\partial F(3,1)}{\partial D_{t+1}} g_{a v}^{D} \\
g_{a v}^{c}+g_{a v}^{d}-\frac{\mu}{1+r} E l_{t+1} g_{a v}^{D}+h_{a v}^{a} \\
-g_{a v}^{d}+h_{a v}^{v}
\end{array}\right]
$$


for the derivatives with respect to $v v$ in rows $1-5$ and derivatives with respect to $a v$ in rows 6-10. It follows from $F_{x a}=F_{x v}=0$ that all second-order derivatives equal zero.

It remains to derive $F_{\sigma_{i}}, i=l, y$. Using the results for the first derivatives $g_{j}^{i}, h_{j}^{k}$ with $i=c, d, D ; j=a, v$ and $k=a, v$, and $E_{t} \varepsilon_{l}=E_{t} \varepsilon_{y}=0$, we find

$$
F_{\sigma_{l}}=\left[\begin{array}{c}
-\beta(1+r) E_{t} u^{\prime \prime}\left(c_{t+1}\right) g_{\sigma_{l}}^{c}+u^{\prime \prime}\left(c_{t}\right) g_{\sigma_{l}}^{c} \\
-\beta(1-\delta) E_{t} u^{\prime \prime}\left(c_{t+1}\right) g_{\sigma_{l}}^{c}+u^{\prime \prime}\left(c_{t}\right) g_{\sigma_{l}}^{c}-\beta \phi E_{t} w^{\prime \prime}\left(\widetilde{v}_{t+1}\right) h_{\sigma_{l}}^{v} \\
\frac{\partial F(3,1)}{\partial c_{t+1}} g_{\sigma_{l}}^{c}-\frac{\mu}{1+r} E l_{t+1} u^{\prime \prime}\left(c_{t}\right) g_{\sigma_{l}}^{c}+\frac{\partial F(3,1)}{\partial D_{t+1}} g_{\sigma_{l}}^{D} \\
g_{\sigma_{l}}^{c}+g_{\sigma_{l}}^{d}-\frac{\mu}{1+r} E l_{t+1} g_{\sigma_{l}}^{D}+h_{\sigma_{l}}^{a}-\left(1-D_{t}\right) E_{t} \varepsilon_{l} \\
-g_{\sigma_{l}}^{d}+h_{\sigma_{l}}^{v}+E_{t} \varepsilon_{l}
\end{array}\right]
$$

and

$$
F_{\sigma_{y}}=\left[\begin{array}{c}
-\beta(1+r) E_{t} u^{\prime \prime}\left(c_{t+1}\right) g_{\sigma_{y}}^{c}+u^{\prime \prime}\left(c_{t}\right) g_{\sigma_{y}}^{c} \\
-\beta(1-\delta) E_{t} u^{\prime \prime}\left(c_{t+1}\right) g_{\sigma_{y}}^{c}+u^{\prime \prime}\left(c_{t}\right) g_{\sigma_{y}}^{c}-\beta \phi E_{t} w^{\prime \prime}\left(\widetilde{v}_{t+1}\right) h_{\sigma_{y}}^{v} \\
\frac{\partial F(3,1)}{\partial c_{t+1}} g_{\sigma_{y}}^{c}-\frac{\mu}{1+r} E l_{t+1} u^{\prime \prime}\left(c_{t}\right) g_{\sigma_{y}}^{c}+\frac{\partial F(3,1)}{\partial D_{t+1}} g_{\sigma_{y}}^{D} \\
g_{\sigma_{y}}^{c}+g_{\sigma_{y}}^{d}-\frac{\mu}{1+r} E l_{t+1} g_{\sigma_{y}}^{D}+h_{\sigma_{y}}^{a}-E_{t} \varepsilon_{y} \\
-g_{\sigma_{y}}^{d}+h_{\sigma_{y}}^{v}
\end{array}\right]
$$

Since $F_{\sigma_{l}}$ and $F_{\sigma_{y}}$ are linear and homogenous in $g_{\sigma_{l}}^{j}$ and $h_{\sigma_{l}}^{k}, F_{\sigma_{l}}=F_{\sigma_{y}}=0$ implies that $h_{\sigma_{l}}^{k}=0$ and $g_{\sigma_{l}}^{j}=0$ with $j=c, d, D ; i=l, y$ and $k=a, v$.

For the second-order derivatives we get

$$
\begin{aligned}
& F_{\sigma_{l} \sigma_{l}}= \\
& {\left[\begin{array}{c}
u^{\prime \prime}\left(c_{t}\right) g_{\sigma_{l} \sigma_{l}}^{c}-\beta\left[\phi E_{t} w^{\prime \prime \prime}\left(\widetilde{v}_{t+1}\right) E_{t}\left(\varepsilon_{l}^{2}\right)+(1-\delta) E_{t} u^{\prime \prime}\left(c_{t+1}\right) g_{\sigma_{l} \sigma_{l}}^{c}+\phi E_{t} w^{\prime \prime}\left(\widetilde{v}_{t+1}\right) h_{\sigma_{l} \sigma_{l}}^{v}\right] \\
\frac{\partial F(3,1)}{\partial c_{t+1}} g_{\sigma_{l} \sigma_{l}}^{c}-\frac{\mu}{1+r} E l_{t+1} u^{\prime \prime}\left(c_{t}\right) g_{\sigma_{l} \sigma_{l}}^{c}+\frac{\partial F(3,1)}{\partial D_{t+1}} g_{\sigma_{l} \sigma_{l}}^{D} \\
g_{\sigma_{l} \sigma_{l}}^{c}+g_{\sigma_{l} \sigma_{l}}^{d}-\frac{\mu}{1+r} E l_{t+1} g_{\sigma_{l} \sigma_{l}}^{D}+h_{\sigma_{l} \sigma_{l}}^{a} \\
-g_{\sigma_{l} \sigma_{l}}^{d}+h_{\sigma_{l} \sigma_{l}}^{v}
\end{array}\right]}
\end{aligned}
$$

and

$$
F_{\sigma_{y} \sigma_{y}}=\left[\begin{array}{c}
-\beta(1+r) E_{t} u^{\prime \prime}\left(c_{t+1}\right) g_{\sigma_{y} \sigma_{y}}^{c}+u^{\prime \prime}\left(c_{t}\right) g_{\sigma_{y} \sigma_{y}}^{c} \\
u^{\prime \prime}\left(c_{t}\right) g_{\sigma_{y} \sigma_{y}}^{c}-\beta\left[(1-\delta) E_{t} u^{\prime \prime}\left(c_{t+1}\right) g_{\sigma_{y} \sigma_{y}}^{c}+\phi E_{t} w^{\prime \prime}\left(\widetilde{v}_{t+1}\right) h_{\sigma_{y} \sigma_{y}}^{v}\right.
\end{array}\right]
$$


$F_{\sigma_{y} \sigma_{y}}$ is linear and homogenous in $g_{\sigma_{y} \sigma_{y}}^{j}$ and $h_{\sigma_{y} \sigma_{y}}^{k}, g_{\sigma_{y} \sigma_{y}}^{j}=h_{\sigma_{y} \sigma_{y}}^{k}=0$. The same holds for $F_{\sigma_{y} \sigma_{l}}$ because $E_{t} \varepsilon_{l} \varepsilon_{y}=0$; and for $F_{x \sigma_{i}}, i=l, y$. Instead, given that $E_{t} \varepsilon_{l}^{2}=1$, $F_{\sigma_{l} \sigma_{l}}=0$ implies

$$
h_{\sigma_{l} \sigma_{l}}^{a}=-h_{\sigma_{l} \sigma_{l}}^{v}=-g_{\sigma_{l} \sigma_{l}}^{d}=\frac{w^{\prime \prime \prime}\left(v_{s s}\right)}{w^{\prime \prime}\left(v_{s s}\right)}
$$

where the other second-order derivatives are found to be zero.

\section{Appendix B: Description of numerical algorithm}

We solve the problem using value function iteration. First, we guess upper bounds $\bar{v}$ and $\bar{a}$ for the durable stock and risk-free assets, respectively, which imply an upper bound for cash-on-hand $\bar{x}=(1+r) \bar{a}+(1-\delta) \bar{v}+y$. The additional constraints $a_{s} \leq \bar{a}$ and $v_{s} \leq \bar{v}$ help us to generate a compact state space. We then solve the problem given these constraints as described below. If either constraint is binding in the solution of the constrained problem, we increase $\bar{v}$ and $\bar{a}$ and iterate again. We proceed analogously for the lower bound which is given by the constraints $a_{\mathrm{s}} \geq \underline{a}$ and $v_{\mathrm{s}} \geq 0$.

We approximate the value function with a high-order Chebychev polynomial. A high-order polynomial is necessary because the value function becomes steep in the region of the state space where agents do not hold any risk-free assets, i.e., for small $x$. We check the precision on a fine grid $x$ between the evaluation nodes. We compare $V^{\text {cheb }}(x)$ to $V(x)$ with

$$
V\left(x_{t}\right)=\max _{D_{t+1}, v_{t+1}, a_{t+1}}\left\{u\left(c_{t}\right)+\beta E_{t}\left(V^{\text {cheb }}\left(x_{t+1}\right)+\phi w\left(\widetilde{v}_{t+1}\right)\right)\right\} .
$$

For the benchmark parameter values, we started with a polynomial of order 29 with 30 evaluation nodes which resulted in $\max \left|V^{\text {cheb }}(x)-V(x)\right|<.0001$. Building on this precise approximation, we were able to reduce the order of the polynomial to 10 and the number of nodes to 15 for computations with other parameter values, achieving the same precision. We also experimented with cubic splines, but found that computational time increased for similar levels of accuracy.

We solve the maximization problem calling the Matlab routine fminsearch, which uses the Nelder-Mead simplex method. To ensure that we find the global maximum, we evaluate

$$
\Lambda \equiv u\left(c_{t}\right)+\beta E_{t}\left(V^{\mathrm{cheb}}\left(x_{t+1}\right)+\phi w\left(\widetilde{v}_{t+1}\right)\right)
$$

on a fine grid of values of $k=\left[D_{t+1}, v_{t+1}, a_{t+1}\right]$ and pick the five values of $\left\{k_{j}^{\text {ini }}\right\}_{j=1: 5}$ that yield the highest values of $\Lambda$. We use these values to initialize the Nelder-Mead simplex method and retrieve the solution $\left\{k_{j}^{\text {sim }}\right\}_{j=1: 5}$. We then choose the value of $\left\{k_{j}^{\mathrm{sim}}\right\}_{j=1: 5}$ that maximizes the value function. If any of the elements of $\left\{k_{j}^{\mathrm{sim}}\right\}_{j=1: 5}$ are within a specified (small) distance of the respective constraints, we additionally check whether setting the respective element equal to the constraint and reoptimizing the other elements yields an improvement. 
For each iteration step $i$, we calculate the maximum iteration errors $\varepsilon_{V} \equiv\left|V^{i}-V^{i-1}\right|, \varepsilon_{a} \equiv\left|a_{t+1}^{i}-a_{t+1}^{i-1}\right|, \varepsilon_{v} \equiv\left|v_{t+1}^{i}-v_{t+1}^{i-1}\right|$, and $\varepsilon_{D} \equiv\left|D_{t+1}^{i}-D_{t+1}^{i-1}\right|$ on the grid of the evaluation nodes. The iteration procedure is terminated when all errors are less than .001. We further check the accuracy of the solution by calculating the analytical first-order conditions. As one can observe in Fig. 2a-c, the FOC are satisfied up to a tolerance of .001 when the constraints are not binding.

To calculate the expected values of $a, v, D, d, c$, and insurance expenditure, we simulate the model for 1,000 periods, discard the first 100 observations and take averages. The results are insensitive to the initial conditions used in the simulation. Except for the retention ratio, all values reported in the table and figures are in percentages of annual average income.

\section{References}

AIYAGARI, S.R. [1994]: “Uninsured Idiosyncratic Risk and Aggregate Savings,” Quarterly Journal of Economics, 109, 659-684.

ALESSIE, R., DEVEREUX, M.P., and WEBER, G. [1997]: “Intertemporal Consumption, Durables and Liquidity Constraints: A Cohort Analysis," European Economic Review, 41, 37-59.

ATTANASIO, O.P. [1999]: “Consumption," in Handbook of Macroeconomics, vol. 1B, ch. 11, J. B. Taylor and M. Woodford (Eds.), Amsterdam: North Holland.

BERTOLA, G., GUISO, L., and PISTAFERRI, L. [2005]: "Uncertainty and Consumer Durables Adjustment," Review of Economic Studies, 72, 973-1007.

CARROLL, C.D. [1997]: "Buffer-Stock Saving and Life Cycle/Permanent Income Hypothesis," Quarterly Journal of Economics, 112, 1-55.

CARROLL, C.D. and KIMBALL, M. [1996]: "On the Concavity of the Consumption Function," Econometrica, 64, 981-992.

CARROLL, C.D. and KIMBALL, M. [2001]: "Liquidity Constraints and Precautionary Saving," NBER Working Paper Series No. 8496.

DEATON, A. [1991]: "Saving and Liquidity Constraints," Econometrica, 59, 1221-1248.

DEATON, A. and LAROQUE, G. [1992]: “On the Behavior of Commodity Prices," Review of Economic Studies, 59, 1-23.

DIAZ, A. and LUENGO-PRADO, M.J. [2005]: "Precautionary Savings and Wealth Distribution with Durable Goods," Northeastern University, mimeo.

DRÈZE, J.H. [1981]: “Inferring Risk Tolerance from Deductibles in Insurance Contracts," The Geneva Papers on Risk and Insurance, 6, 48-52.

EECKHOUDT, L., GOLLIER, C., and SCHLESINGER, H. [1991]: "Increases in Risk and Deductible Insurance," Journal of Economic Theory, 55, 435-440.

EECKHOUDT, L., MEYER, J., and ORMISTON, M.B. [1997]: “The Interaction between the Demands for Insurance and Insurable Assets," Journal of Risk and Uncertainty, 14, 25-39.

EHRLICH, I. and BECKER, G.S. [1972]: "Market Insurance, Self-Insurance, and Self-Protection," Journal of Political Economy, 80, 623-648.

FERNANDEZ-VILLAVERDE, J. and KRUEGER, D. [2002]: "Saving Over the Life Cycle: How Important are Consumer Durables?," in Proceedings of the 2002 North American Summer Meetings of the Econometric Society: Macroeconomic Theory.

FINANCIAL SERVICES FACT BOOK [2004]: Insurance Information Institute, New York.

GOLLIER, C. [1994]: "Insurance and Precautionary Capital in a Continuous-Time Model," The Journal of Risk and Insurance, 61, 78-95.

GOLLIER, C. [2003]: “To Insure or Not to Insure?: An Insurance Puzzle,” Geneva Papers of Risk and Insurance Theory, 28, 5-24.

GRUBER, J.W. and MARTIN, R.F. [2003]: "Precautionary Savings and the Wealth Distribution with Illiquid Durables," Board of Governors of the Federal Reserve System, International Finance Discussion Papers No. 773. 
HALIASSOS, M. and MICHAELIDES, A. [2001]: "Calibration and Computation of Household Portfolio Models," In: Household Portfolios, L. Guiso, M. Haliassos, and T. Jappelli (Eds.), Cambridge: MIT Press, pp. 55-102.

KIMBALL, M.S. [1990]: “Precautionary Savings in the Small and in the Large," Econometrica, 58, 53-73.

LAM, P.-S. [1991] "Permanent Income, Liquidity, and Adjustments of Automobile Stocks: Evidence from Panel Data," Quarterly Journal of Economics, 106, 203-230.

LUENGO-PRADO, M.J. [2006]: "Durables, Nondurables, Down Payments and Consumption Excesses," Journal of Monetary Economics, 53, 1509-1539.

MEHRA, R. and PRESCOTT, E.C. [1985]: "The Equity Premium: a puzzle," Journal of Monetary Economics, 15, 145-161.

RAVIV, A. [1979]: “The Design of an Optimal Insurance Policy," American Economic Review, 69, 84-96.

SCHMITT-GROHÉ, S. and URIBE, M. [2001]: "Solving Dynamic General Equilibrium Models Using a Second-Order Approximation to the Policy Function," CEPR Working Paper No. 2963.

WALDMAN, M. [2003]: "Durable Goods Theory for Real World Markets," Journal of Economic Perspectives, 17, 131-154.

SMITH, E. and WRIGHT, R. [1992]: "Why is Automobile Insurance in Philadelphia So Damn Expensive?" American Economic Review, 82, 756-772. 